IZA DP No. 6651

Fostering the Emancipation of Young People: Evidence from a Spanish Rental Subsidy

Ainhoa Aparicio-Fenoll

Veruska Oppedisano

June 2012 


\title{
Fostering the Emancipation of Young People: Evidence from a Spanish Rental Subsidy
}

\author{
Ainhoa Aparicio-Fenoll \\ Collegio Carlo Alberto \\ and IZA \\ Veruska Oppedisano \\ UCL
}
Discussion Paper No. 6651
June 2012

IZA

P.O. Box 7240

53072 Bonn

Germany

Phone: +49-228-3894-0

Fax: +49-228-3894-180

E-mail: iza@iza.org

Any opinions expressed here are those of the author(s) and not those of IZA. Research published in this series may include views on policy, but the institute itself takes no institutional policy positions.

The Institute for the Study of Labor (IZA) in Bonn is a local and virtual international research center and a place of communication between science, politics and business. IZA is an independent nonprofit organization supported by Deutsche Post Foundation. The center is associated with the University of Bonn and offers a stimulating research environment through its international network, workshops and conferences, data service, project support, research visits and doctoral program. IZA engages in (i) original and internationally competitive research in all fields of labor economics, (ii) development of policy concepts, and (iii) dissemination of research results and concepts to the interested public.

IZA Discussion Papers often represent preliminary work and are circulated to encourage discussion. Citation of such a paper should account for its provisional character. A revised version may be available directly from the author. 


\section{ABSTRACT}

\section{Fostering the Emancipation of Young People: Evidence from a Spanish Rental Subsidy}

In Southern Europe youngsters leave the parental home significantly later than in Northern Europe and United States. In this paper, we study the effect of a monthly cash subsidy on young adults' emancipation, family formation, and fertility. The subsidy, introduced in Spain in 2008 , is conditional on young adults renting accommodation, and it amounts to almost 20 percent of the average youngsters' wage. Our identification strategy exploits the subsidy eligibility age threshold to assess the causal impact of the cash transfer. Difference-inDifferences and Regression Discontinuity estimates show that the policy increases emancipation rates by $0.9-2.3$ percentage points, couple cohabitation by 1.2-2.4 percentage points, and the probability of having children by 4.8-8.1 percentage points for 22 year-olds compared to 21 year-olds. The effect is larger among young adults earning lower incomes and living in high rental price areas. This is consistent with the hypothesis that youngsters delay emancipation and family formation because they are budget constrained.

\section{NON-TECHNICAL SUMMARY}

We study the case of a rental subsidy targeted to young people in Spain. We show that it is possible to induce young people to leave the parental home earlier by giving them economic incentives. The policy also increases couple cohabitation and fertility rates. We also find that poorer individuals react more to the subsidy. This suggests that the program should be targeted to poorer individuals. Moreover, the higher impact of the policy for young adults living in high rental price regions indicates that the policy design should take into account not only individual's income but also housing prices. Accounting for these two aspects would allow the policy to remove barriers to emancipation for young adults who are too poor to afford renting accommodation, while limiting the cost of the program and potential increases in housing prices as a consequence of the higher demand for accommodation.

JEL Classification: J1, H2, I3

Keywords: rental subsidy, conditional cash transfer, youth emancipation, family formation, fertility

Corresponding author:

Ainhoa Aparicio Fenoll

Collegio Carlo Alberto

Via Real Collegio 30

Moncalieri (TO) 10024

Italy

E-mail: ainhoa.aparicio@carloalberto.org

\footnotetext{
* The authors thank for useful suggestions Marco Manacorda, Andrea Ichino, Till von Wachter, Valerie Lechene, Sebastian Galiani, Christian Bartolucci, Luna Bellani, seminar participants at UCL, Collegio Carlo Alberto, University of Bologna, CSEF, and participants at CEPS/INSTEAD workshop. Veruska Oppedisano acknowledges the generous support of the Marie Curie Intra European Fellowship for Career Development while based at UCL.
} 


\section{Introduction}

Over the past three decades Southern European countries have witnessed a sharp increase in the fraction of young people living with their parents. In 2010, almost 60 percent of young people in the 18-34 age bracket still lived in their parental homes in Italy, Spain, Portugal, and Greece, whilst that statistic is below 40 percent in France, the UK, and the Netherlands, and as low as 20 percent in Norway, Sweden, and Finland. ${ }^{1}$ Late emancipation is of primary concern for policy, because it may critically affect family formation decisions, overall fertility rates, youth labour supply, and the sustainability of pay-as-yougo pension systems.

Economic literature finds that perceived youngsters' job insecurity, limited access to credit markets, high housing prices, and low lifetime earnings play an important role in delaying youngsters' adult life (Becker et al., 2010; Martins and Villanueva, 2006; Giannelli and Monfardini, 2003). According to the 2007 Eurobarometer survey, lack of financial resources is the main reason for staying in the parental home. When asked the reason that young adults remain in their parents' home longer than they used to, 44 percent of young Europeans reply they cannot afford to move out, and 28 percent think that there is not enough affordable housing available. However, 16 percent believe that staying with their parents allows them to live more comfortably and with less responsibilities.

In this paper, we investigate the hypothesis that youngsters delay emancipation and family formation because they are budget constrained. We study the impact of a conditional cash transfer contingent on young adults' renting accommodation. The theoretical analysis suggests that, if young adults have preferences for independence, the combination of income and price effects of the policy is expected to increase emancipation and couple cohabitation rates, especially for youngsters at the lower tail of the income distribution and those who live in high rental price areas. The income effect of the policy on young adults already emancipated may increase the consumption of goods complementary to cohabitation, as fertility.

The policy under analysis has been implemented in Spain beginning in January 2008, in order to promote youngsters' emancipation. The analysis of the Spanish policy is an interesting case because Spain shares similar emancipation patterns, housing market and institutional traits with other southern European countries. The policy, called Basic Income for Emancipation ("Renta basica de emancipacion"), offers to young people in the age bracket 22-29 a monthly monetary subsidy of $€ 210$ for a maximum period of four years, conditional on renting accommodation. This amount is equivalent to almost 20 percent of the average gross salary of a young person. The policy applies only after the individual turns 22 years old. Given that individuals cannot manipulate their age, the subsidy is "as if" randomly assigned to individuals around the age cutoff.

We use two estimation methods. First, we apply a Difference-in-Differences strategy, comparing outcomes for 21 and 22 year-olds before and after the policy

\footnotetext{
${ }^{1}$ Source: Eurostat, EU-SILC.
} 
implementation. Second, we adopt a Regression Discontinuity design that takes advantage of the fact that eligibility turns on when an individual turns 22 . In this setting, the outcomes of eligible young people aged 22 are compared with those of non-eligible youngsters aged 21 .

Using data from the Spanish Labour Force survey and the Household Budget survey, we find that the subsidy increases the probability of emancipating by 0.9-2.3 percentage points for 22 year-old youngsters with respect to 21 ones. Relative to the average emancipation rate in the population of interest, this implies an increase in emancipation in the range of 14-18 percent. While the policy does not affect the marriage rate, it increases couple cohabitation by 1.22.4 percentage points, which implies an increase of 11-22 percent points relative to the sample mean. The subsidy has a stronger effect for young adults at the lower tail of the income distribution, and for those living in high rental price areas. This is consistent with the hypothesis that young adults with a positive taste for independence would emancipate and form a household earlier if they had higher incomes or if they faced lower rental prices. Emancipated individuals, who mostly benefit from the income effect of the policy, increase the probability of having at least one kid by 4.8-8.1 percentage points, and by 13-22 points relative to the sample mean. All results are robust to alternative specifications.

This paper makes a contribution to the burgeoning literature on heterogeneity in living arrangements in developed countries. A branch of the literature focused on the importance of economic conditions, exploring the effects of youngsters' job insecurity, access to credit, and housing prices. Evidence on the role of job insecurity is mixed. Becker et al. (2010) analyze the relationship between youth emancipation and job insecurity on a sample of cross-European and Italian data, and find that coresident rates are positively related with youngsters' job insecurity and parental job security. Garcia-Ferreira and Villanueva (2007), using a legally-induced sharp increase in firing costs as an identification strategy, find that there is no causal relationship between youngsters' employment risk and living arrangements. With regard to housing costs, Martins and Villanueva (2009) document the negative causal relationship between household formation and the cost of credit. Martínez-Granado and Ruiz-Castillo (2002), using data on Spanish youth, find that the rental-equivalent values of housing services and housing prices are negatively correlated with the probability of living independently. Ermish (1999) adds to the analysis the option of returning to parental home, finding that tighter housing markets significantly retard home leaving and encourage returns to the parental home. Our results support the importance of economic conditions by indicating that young adults delay emancipation because they are budget constrained.

Another branch of this literature highlights the role of culture in shaping living arrangements. Giuliano (2007) argues that the liberal attitudes brought by the sexual revolution allowed young people in Southern European countries to obtain their sexual independence at home while still enjoying the benefits of living with their parents. Manacorda and Moretti (2006) focus on parental preferences for having children living at home, showing that if children have a 
preference for living on their own, some parents are willing to trade off their own consumption to bribe their children into staying at home. While recognizing the importance of preferences in shaping living arrangements, our paper abstracts from this source of heterogeneity, and focuses on changes in the budget constraint as a result of the policy.

The paper is organized as follows. Section 2 describes the institutional settings of the policy under analysis and its impact on young adults' living arrangements; Section 3 details the identification strategy, Section 4 outlines the results, Section 5 analyses the robustness of the results, and Section 6 concludes.

\section{The Spanish rental subsidy}

\subsection{Institutional background}

Announced in September 2007 and enacted since January 2008, the Basic Rent for Emancipation is a monetary subsidy introduced by the Spanish Ministry of Housing with the aim of fostering youngsters' emancipation. The government expected to achieve this goal by helping young individuals to cope with rental expenses.

The subsidy pays $€ 210$ monthly for a maximum period of four years. Eligibles may also benefit from an additional $€ 120$ to pay the bank guarantee associated with the rental contract, and a one-time $€ 600$ loan to pay the rent deposit in case they sign a new rental contract. To appreciate the magnitude of the subsidy, it can be useful to compare it with the average Spanish youngsters' monthly earnings. Average gross monthly earnings of young people in the 20-24 age brackets amount to $€ 1,100$ in $2008 .^{2}$ The subsidy is therefore equivalent to almost 20 percent of the average gross salary of a young person. Moreover, young people who receive the subsidy devote on average 25 percent of their income to pay the rent, while they would devote 42 percent to pay the same amount in the absence of the subsidy. Finally, the subsidy is likely to make emancipation affordable for many youngsters, as the maximum affordable rent for the average young household is $€ 560$, while the average rent $€ 626$. By July 2011 , the subsidy was given to 35 percent of households headed by an individual aged 22 to $29 .^{3}$

To be eligible for the subsidy, youngsters need to be in the 22 to 29 age bracket and have a rental contract. This includes all individuals that had a rental contract before becoming eligible ${ }^{4}$. Those who do not have a rental contract may request the subsidy conditional on providing the contract signed in three months time. Eligibles need to certify that they are employed, autonomous workers, grant holders, or receivers of a periodic social benefit (including unemployment benefit). The latter are also required to have worked for at least six months or

\footnotetext{
${ }^{2}$ Source: Spanish Wage Structure Survey, 2008.

${ }^{3}$ Source: Spanish Ministry of Housing.

${ }^{4}$ Note that the policy provides no incentives to 21 year-olds to postpone emancipation. Emancipated 21 year-olds will be entitled to the same amount of subsidy as soon as they become eligible.
} 
provide evidence that the social benefit will last for at least six months. For all the eligibles, the net source of income must not exceed $€ 1,500$. EU citizens and non-EU citizens with a permanent resident permit are eligible. If several individuals are sharing accommodation, each young adult entitled to the subsidy receives a share of the subsidy proportional to the number of people who sign the rental contract.

\subsection{Theoretical framework}

The rental subsidy is a conditional cash transfer contingent on renting accommodation. This section illustrates the individual decision making process in the presence of the conditional cash transfer. The individual, whose decision problem is shown in Figure 1, can consume housing, depicted on the horizontal axis, and all other goods, on the vertical axis. $h^{*}$ corresponds to the minimum housing level in correspondence of which a rental contract exists in the market, and represents the conditionality requirement. Consumption of housing is zero if the individual lives with her parents (point $A$ in the graph), and higher or equal to $h^{*}$ if the individual is emancipated. When the individual consumes a positive quantity of housing, the opportunity set is described by the budget constraint $B C$. The negative slope of the line $B C$ is given by the rental price $p$, which describes the trade-off between the consumption of other goods and housing.

The pre-policy budget constraint is represented by point $A$ and the segment $B C$, with a discontinuity at $0<h<h^{*}$. Eligibility causes the budget line to shift up without changing its slope in correspondence of $h \geq h^{*}$. The feasible budget constraint for eligibles is described by the line $D E$. The difference $D-B$ is proportional to the real cash transfer implied by the program.

Differences across individuals in incomes, rental prices, and preferences may explain why some individuals are emancipated or not. To keep the exposition simple, we assume that individuals have the same preferences, denoted by the indifference curve passing by point $A$ but differ in their budget constraints. Point $B^{\prime}$ shows the intersection between the indifference curve that passes through $A$ with the vertical line at $h^{*}$. The vertical difference $B^{\prime}-B$ represents the minimum cash transfer that will make individual $A$ indifferent between living with her parents and emancipating. Some individuals with preferences described by the indifference curve passing by point $A$ and budget constraint $B^{\prime} C^{\prime}$ may be already emancipated before the policy. If emancipation rates are higher among wealthier individuals before the program, the policy should have a stronger effect on youngsters at the lower tail of the income distribution.

We now consider the case in which individuals with the same preferences face different rental prices. The budget constraint $B F$ implies a lower rental price $p$ than $p$. Point $B^{\prime \prime}$ shows the intersection between the indifference curve that passes through $A$ and the budget constraint $B F$ where the individual is indifferent between living in the parents' home and emancipating. Absent the policy, some youngsters facing rental prices $p^{\prime}<p$ may be already emancipated. 
This suggests that the policy is expected to have stronger effects for young adults living in high rental price regions.

For individuals who comply with the conditionality, the policy has both income and price effects, as it makes renting a cheaper option. For individuals who would rent accommodation even in the absence of the policy, conditionality is not binding, and the policy is likely to have only a pure income effect, represented in Figure 1 by the parallel upward shift of the budget line.

We test these hypotheses in the following way. First, we examine whether the policy increases emancipation and cohabitation rates of eligible individuals, relative to ineligible. Second, we examine whether emancipation and cohabitation rates increase more among eligible youngsters at the lower tails of the income distribution than at higher tails. Similarly, we test whether these rates increase more for young adults resident in high rental price areas than for those living in low price areas. Finally, we analyze the income effect of the policy on the sample of emancipated individuals on the probability of having children, a good that is complementary to couple cohabitation.

Two remarks are in order. First, previous studies have documented the role of preferences in shaping living arrangements (Giuliano 2007 and Manacorda and Moretti 2006). Our analysis abstracts from differences across individuals' preferences to focus on differences across income opportunities and rental prices. Second, our theoretical analysis describes a partial equilibrium. Nevertheless, the policy may induce an increase in rental prices (Susin 2002). In Section 5, we analyze the extent to which the policy affected rental prices.

\section{$3 \quad$ Empirical strategy}

\subsection{Data}

Our main dataset consists of the 2006-09 waves of Spanish Labor Force Survey, which surveys 165,000 individuals every quarter. The data contain a wide range of information on individuals' demographic characteristics and labor market outcomes. We exploit the cross sectional version of the data as the panel version does not allow us to identify households, and therefore emancipation. The estimation sample varies from 7,914 to 109,944 individuals according to the chosen specification. We use all quarters of 2006-09 samples for the Differencein-Differences analysis, the post-policy 2008-09 samples for the Regression Discontinuity analysis, and the pre-policy 2006-07 samples to run the placebo tests. Effective emancipation, i.e. building up an independent household, is measured by a dummy equal to one if the individual lives out of parental home and zero otherwise. Cohabitation is defined with a dummy equal to one if the individual lives with his/her partner, and zero otherwise. Fertility is a dummy equal to one if the individual has one or more children, and zero otherwise.

We also use the Household Budget Survey, a yearly survey of about 60,000 individuals run since 2006 with the main purpose of registering detailed information on individuals' expenditures. BHS collects data on individuals' income. 
Some individuals report the exact amount of net monthly income, whilst others report the interval. The two variables are equally distributed. We exploit the information on individuals' income for two purposes: (i) checking lack of manipulation around the income eligibility cutoff; (ii) assessing the heterogeneous reaction to the policy of individuals with different levels of income. To this purpose, we select only the sample of 21 and 22 year-olds excluding individuals whose income is missing (approximately 20 percent of the sample of employed individuals).

Finally, we merge the LFS with the 2006-09 waves of the Fotocasa survey, which collects information on yearly rental prices per square meter, by region. We compute the country average rental price across the 17 Spanish regions before the policy implementation and define high rental price regions as those where rental prices are above the country average.

\section{$3.2 \quad$ Identification strategy}

\subsubsection{Difference-in-Differences}

To estimate the effects of the rental subsidy on youngsters' emancipation we apply two complementary strategies, Difference-in-Differences and Regression Discontinuity. The two exploit the fact that individuals are entitled to the subsidy only after they turn 22 years old. The D-i-D strategy consists in comparing the change in outcomes after the introduction of the subsidy for eligible individuals aged 22 (the treatment group) and non-eligible aged 21 (the comparison group). We extend the estimation of the D-i-D model to the inclusion of 20 year-olds (comparison group) and 23 year-olds (treatment group) as well. ${ }^{5}$ The D-i-D model has the advantage that it allows us to get rid of time trends in emancipation.

We exploit two sources of variation. One source of variation is determined by the year the youngster is interviewed. The young people interviewed in 2006 and 2007 did not benefit from the program, since the rental subsidy only came into force in January 2008, whilst individuals aged 22-29 interviewed in 2008 and 2009 were fully eligible.

The other source of variation arises from age. Due to the eligibility criteria established by the law, individuals younger than 22 and older or equal than 30 were not entitled to the subsidy. Youngsters can receive the monthly subsidy for a maximum of 4 years, implying that 22 year-olds are exposed to the program for a longer period than 26-29 year-olds. For this reason, we focus our analysis on comparing 21 and 22 year-olds rather than 29 and 30 year-olds. People slightly older than 22 are entitled to the subsidy while those slightly younger are not,

\footnotetext{
${ }^{5}$ A potential statistical threat to our strategy may arise because the sampling occurs at the household level in both LFS and HBS. If within each household there are two siblings aged 21 or 22 years, the sample of not emancipated youngsters would be over-represented. To make the sampling comparable across emancipated and not emancipated young adults, we randomly chose one individual across households with two or more siblings aged 21 or 22 years.
} 
but otherwise the two groups have very similar characteristics. ${ }^{6}$

Our estimates provide a lower bound of the true effect of the policy for two reasons. First, 22 year-old are less likely to fulfill the requirements to be entitled to the subsidy than 30 year-old. Second, non-eligibles 21 year-old youngsters, who are not financially constrained, may leave parental home before becoming eligibles anticipating that the following year they will be entitled to the subsidy.

It is important to note that in both cases we are estimating intention to treat effects. The reason is twofold. First, we do not observe who actually receives the subsidy. Second, treatment may not be exogenous if there are unobserved differences between individuals receiving the subsidy and those who do not. Examining the outcomes by subsidy eligibility removes this source of bias and allows us to identify an intention to treatment effect.

We define eligibility on the basis of the age threshold induced by the policy. We do not account for both the income threshold and the job history criteria. Disregarding the income cutoff is not expected to undermine our results because, as we show in the next section using HBS data, the fraction of youngsters in the sample who earn a net monthly income higher than $€ 1,500$ is considerably low. Moreover, data evidence absence of manipulation around the income cutoff (see Figure 3). As regard job history, the law assesses that individuals who were employed for at least six months or who have just signed a working contract, whose length is at least six months, are eligible for the benefit. Omitting the employment status when defining eligibility does not constitute a threat to our identification strategy. First, because employment is not a necessary condition for receiving the subsidy; eligibles include grants holders and social benefits recipients. Second, because the requirement holds only when the individual applies for the subsidy. After that, lack of employment does not imply the benefit's withdrawal.

The main assumption behind the D-i-D strategy is that the trends of the average outcome of interest for treatment and control groups would have been parallel in the absence of the policy. In order to support this assumption, we show evidence that the trends were parallel before the policy was implemented. Graph 2 shows the trends of average yearly emancipation rates of 21 and 22 yearolds using the 2000-09 LFS data. The graph clearly illustrates a parallel trend in emancipation rates before 2008, with 21 year-olds featuring lower emancipation rates than 22 year-olds. In 2008, when the policy was introduced, the two lines diverge, consistently with the main hypothesis of the D-i-D strategy. The declining trend in emancipation of 21 year-olds after 2008 could be explained by the economic recession, consistently with findings in Ermisch (1999). An alternative explanation could rely on 21 year-olds postponing emancipation until they become eligible. The policy design does not provide such an incentive and in Section 5 we rule out this explanation. The placebo tests in Section 5

\footnotetext{
${ }^{6}$ It is important to consider whether the size of the two cohorts varied over time in order to assess the presence of composition effects. The Spanish registry office shows that the cohort size of 21 year-olds did not substantially change between 2007 and 2008, and the eligible 22 year-olds cohort decreased by 0,004\%, passing from 568,072 units in 2007 to 565,621 in 2008. The drop is negligible, but if anything, it should negatively bias the estimates of the policy.
} 
constitute further evidence on the parallel trend assumption.

To obtain an estimate of the change in youth emancipation attributable to the subsidy from a D-i-D strategy, we implement a regression analysis of the following form:

$$
Y_{i j t}=\alpha_{j}+\eta_{t}+\beta \alpha_{j} \eta_{t}+\delta X_{i}+\varepsilon_{i t j}
$$

where $Y_{i j t}$ is the outcome of interest for individual $i$ of age $j$, interviewed at time $t, \alpha_{j}$ is a dummy variable for age higher or equal to $22, \eta_{t}$ is a year dummy equal to one for individuals interviewed in 2008 and after, and zero otherwise. This dummy absorbs any time-specific variation between 2007 and 2008. The coefficient $\beta$ measures the intention to treat effect, i.e. the average effect of the subsidy for the population of eligibles. $X_{i}$ controls for individuals' observable characteristics: province of residence fixed effects, month and year of birth fixed effects, gender, immigration status, and educational level dummies. In addition, the regression includes quarter dummies, which capture the "seasonality effect", i.e., any systematic differences in emancipation rates implied by the calendar period of the year.

The second specification allows us assessing whether the policy was more effective for youngsters at the lower tail of the income distribution. The following equation is estimated using data from the HBS survey, which provides information on individuals' monthly income:

$$
Y_{i j t z}=\alpha_{j}+\eta_{t}+\sum_{k} \zeta_{k} \alpha_{j} \eta_{t} \mu_{k}+\sum_{k} \mu_{k}+\sum_{k} \alpha_{j} \mu_{k}+\sum_{k} \eta_{t} \mu_{k}+\delta X_{i}+\varepsilon_{i t j}
$$

where $\mu_{k}$ are three income dummies: one equal to one if monthly income is less or equal to $€ 500$, and zero otherwise; a dummy equal to one if the income is higher than $€ 500$ and less or equal to $€ 1,000$, and zero otherwise; finally, a dummy equal to one if the income level is higher than $€ 1,000$ and less or equal to $€ 1,500$. The parameters of interest are $\zeta_{k}$. The coefficient corresponding to the lowest level of income, according to the analysis in Section 2.2, should be positive.

The second specification uses as an additional control group that of eligible young adults who live in a low rental price area, facing a budget constraint flatter than in high rental price areas. We estimate the following equation:

$$
Y_{i j t z}=\alpha_{j}+\eta_{t}+H_{z}+\theta \alpha_{j} \eta_{t} H_{z}+\alpha_{j} \eta_{t}+\alpha_{j} H_{z}+\eta_{t} H_{z}+\delta X_{i}+\varepsilon_{i t j}
$$

In equation 3, the subscript $z$ indicates the region where the young adult lives. $H_{z}$ is a dummy equal to one if the average price of a square meter of rental housing in the region of residence in 2007 is higher than the mean Spanish value. The parameter of interest is $\theta$, which captures the effect of the interaction between the age dummy, the post-policy dummy and the dummy of high rental price region of residence. The coefficient $\theta$ measures the different propensity to leave parental home between eligible 22 year-olds living in a high 
rental price area and eligibles living in a low rental price area after the policy implementation. If the policy is more effective for young adults living in high rental prices areas, $\theta$ should be positive.

This strategy relies on the fact that the subsidy amounts to $€ 210$, regardless the area of residence, which allows us to attribute the heterogeneous impact of the subsidy between high and low price areas to differences in housing affordability. The reliability of this strategy would be threatened if some eligible youngsters migrate to areas with lower rental price in order to benefit most from the subsidy. If migration towards lower rental price area drives up the rental price, the definition of high/low rental price area would be endogenously affected. To rule out this concern, we define high and low rental price areas on the basis of the region rental price in 2007, before the policy was implemented.

Table 1 shows summary statistics for the samples used in the first specification of the D-i-D estimation, including youngsters aged 21 and 22 in 2007 and 2008. The first panel of the table shows summary statistics of the Labor Force Survey; panel B those of the Household Budget Survey; and panel C Fotocasa statistics on rental prices. In LFS, 15.6 percent of the sample is emancipated, and 9 percent cohabit. 27 percent of emancipated youngsters have at least a child. Half of respondents are male. Roughly 14 percent are immigrants. 10 percent of the sample has tertiary education, 80 percent secondary education and the rest have primary education. Descriptive statistics are similar in panel $\mathrm{B}$, although less precise due to the lower number of observations. ${ }^{7}$ The average net monthly income amounts to $€ 877,5,13$ percent of the sample earns less than $€ 500,64$ between $€ 500$ and 1,000; 20 percent less than $€ 1,500$, and the remaining more than $€ 1,500$. In panel $\mathrm{C}$, the average rental price per square meters is $€ 8.37$. Rental prices are higher than the average in 35 percent of the Spanish regions.

The basic idea behind the D-i-D identification strategy can be illustrated using a simple two-by-two table. Table 2 presents the change in emancipation, cohabitation, and fertility between 2007 and 2008 for 21 and 22 year-olds. Average emancipation, cohabitation and fertility (conditional on being emancipated) dropped over the two years for 21 year-olds, whilst they increased for 22 year-olds. The simple unconditional differences indicate that the subsidy significantly increases emancipation by 2.7 percentage points, cohabitation by 3.2 percentage points, and fertility by 8.2 percentage points.

\subsubsection{Regression Discontinuity}

A complementary strategy takes advantage of the fact that benefit eligibility "turns on" when an individual turns 22. In this setting, outcomes of eligible youngsters aged 22 are compared to those of non-eligible aged 21.

The key feature of this assignment mechanism is that eligibility is defined on the basis of an individual's age. As the assignment variable is based on time, it cannot be manipulated. However, another eligibility criterion requires

\footnotetext{
${ }^{7}$ Differences in educational levels between the two surveys depend on differences in the coding of educational level.
} 
individuals to earn a regular net monthly source of income lower than $€ 1,500$. The Spanish Labor Force Survey data do not provide information on individuals' income. We thereby use data from the Spanish Households Budget Survey (HBS) to show lack of manipulation at the $€ 1,500$ threshold. Figure 3 shows the histogram of the net monthly income of 22 year-olds in 2007 and 2008. The first observation is that the two distributions are very similar, and the 2008 estimate does not feature any jump on the left of the threshold as one would expect if manipulation had occurred. The second observation concerns the distribution itself: in 2008, less than 5 percent of the sample of 22 year-olds earned more than $€ 1,500$ a month. In an unreported Figure, we replicate the same exercise for the subsample of individuals who declare a precise income level. Also in this case, the 2008 distribution does not present any jump at the $€ 1,500$ cutoff and features a very low number of individuals at the right of the cutoff. Consistently, the Kolmogorov-Smirnov test of equality does not reject the hypothesis of equality of income distributions before and after the policy.

In this specification, the outcomes are estimated as follows:

$$
Y_{i j}=\beta \alpha_{j}+f\left(m_{j}\right)+\gamma f\left(m_{j}\right) \alpha_{j}+\delta X_{i}+\varepsilon_{i j}
$$

where $Y_{i j}$ is the outcome of interest, $\alpha_{j}$, as in Equation 1, is a dummy that takes on a value of one for observations 22 and older, and zero otherwise. The regression includes a polynomial in age, $f\left(m_{j}\right)$, computed in months and centered to take value of zero at 264 months. The polynomial is fully interacted with the $\alpha_{j}$ dummy to allow for different age profiles at both sides of the 22 cut off. As in the D-i-D specification, $X_{i}$ includes the whole set of individual controls, province fixed effects, gender, immigration status, educational level dummies, quarter of interview, and month and year of birth dummies. The parameter of interest is $\beta$, which measures the size of the discrete change of the outcome when people turn 22 and become eligible for the rental subsidy. We select the sample of individuals with age 21 or 22 , and estimate different specifications including individuals who are interviewed three, six, nine and twelve months around the month they turn 22. In contrast to the D-i-D strategy, the sample includes only the post-policy period.

The second specification, which assesses the differential impact of the policy for different income levels, reads as follow:

$$
Y_{i j}=f\left(m_{j}\right)+\sum_{k} \zeta_{k} \alpha_{j} \mu_{k}+\sum_{k} \mu_{k}+\gamma f\left(m_{j}\right) \alpha_{j}+\delta X_{i}+\varepsilon_{i j}
$$

where $\mu_{k}$ are dummies for the three levels of income. The third specification uses as an additional control group that of eligible young adults who live in their parental house in a low rental price area. This allows us to estimate a triple difference model as follows:

$$
Y_{i j z}=f\left(m_{j}\right)+\theta \alpha_{j} H_{z}+H_{z}+\gamma f\left(m_{j}\right) \alpha_{j}+\delta X_{i}+\varepsilon_{i j}
$$

In equation $6, \theta$ measures the differential trend for the propensity to live parental home between 2007 and 2008 among eligible 22 year-old who live in a 
high rental price area with respect to those living in a low rental price area.

\section{Results}

\subsection{Emancipation}

Table 3 presents estimates of the coefficient $\beta$ in equations 1 and 4 . The dependent variable is a dummy equal to one if the individual does not live with her parents, and zero otherwise. The first four columns show estimates from the D-i-D strategy: in the first column we make use of the 2007-08 samples and the 21 and 22 age groups, in the second we add 20 and 23 age groups to the analysis; in the third we make use of 2006-09 and the 21 and 22 age groups and in the fourth column we include the 2006-09 samples and the 20 to 23 age groups. Subsequent columns present estimates from the RDD strategy using the post-policy 2008-09 samples. The RDD specifications include different age intervals before and after the threshold $( \pm 3, \pm 6, \pm 9, \pm 12$ months). For all age intervals, we present two RDD specifications; one that controls for the linear trend in age and another for the quadratic trend. In both cases, the polynomial is fully interacted with the 22 age dummy. ${ }^{8}$ All estimates control for the set of individual variables described in Section 3.

Estimates from the D-i-D strategy in the first columns show that the probability of being emancipated increased significantly by 0.9-1.9 percentage points for 22 year-olds with respect to ineligible 21 year-old youngsters. Subsequent columns (5-8) show the RDD estimates controlling for a linear polynomial in age. Estimates are all significant and vary between 1.2-2 percentage points. Similar results are obtained in columns 9-12, where we control for a second-order polynomial in age. The coefficients are consistent with preliminary evidence of the unconditional means presented in Table 2, where the effect of the policy $(+2.7$ percentage points) was slightly overestimated. Relative to the baseline emancipation rate among youngsters $(15.6 \%)$, the effect ranges from a 14 to a 18 percent increase.

A possible concern is related to individuals emancipating just after they graduated from university. If this is the general rule, and there are more graduates among 22 year-olds than 21 year-olds, our results could be driven by differences in graduation rates between treatment and control groups. The positive coefficients in the RDD specifications including individuals 3 and 6 months around the age cutoff help addressing this concern. These specifications compare individuals who are typically enrolled in the same academic year and hence, should complete education at the same time. However, one could still worry that older students in the class graduate earlier. As we show in Section 5, estimates of a placebo RDD performed in the pre-policy period indicates that this effect is not significant.

\footnotetext{
${ }^{8}$ When we control for a cubic polynomial in age, although none of the variables in the polynomial are significant, estimates are consistent with those reported.
} 
We now assess whether the policy was more effective for youngsters at the lower tail of the income distribution. To this, we use data from the HBS survey, which provides information on individuals' monthly income. This strategy relies on the fact that the policy did not affect individuals' earnings. We test this assumption estimating the main equation with income as a dependent variable. The effect of the policy is not significantly different from zero in all specifications.

We define three income dummies: a dummy that is equal to one if income is less or equal to $€ 500$, and zero otherwise; a dummy that is equal to one if income is higher than $€ 500$ and less or equal to $€ 1,000$, and zero otherwise; and finally, a dummy that takes a value of one if income is higher than $€ 1,000$ and less or equal to $€ 1,500$, and zero otherwise. We interact these dummies with the treatment variable. The sample does not include the few individuals earning more than $€ 1,500$ because their inclusion would cause multicollinearity among the income dummies.

Table 4 presents the estimates of the treatment variable interacted with the three income cutoffs using data in the $\mathrm{HBS}^{9}$. Estimates show that the probability of being emancipated increases with income. The estimated interactions between the treatment dummy and the three income cutoffs indicate that young adults who experience the highest increase in the propensity to emancipate are those earning lower incomes, consistently with the predictions derived in Section 2.2. The D-i-D specifications show that the probability of being emancipated increases by 18 percentage points for individuals who earn $€ 500$ or less, and RDD estimates show that the increase amounts to 19-35 percentage points for the same group of individuals.

The coefficient of the interaction with the dummy $€ 1,000-1,500$ is negative and significant in one specification. A possible explanation for this result relies on the fact that the higher demand for renting accommodation implied by the policy may make the search more costly. Given that wealthier individuals face higher search costs (they have higher opportunity cost of not working), they may be discouraged from emancipating by the increase in demand for renting accommodation.

We check the validity of our results to an alternative sample subdivision: that of individuals earning more and less than the median income value. Although the interactions of interest are estimated with less precision, they are consistent with results in Table 4.

In the third specification we test whether the effect of the policy is different for youngsters who live in high rental price regions. Table 5 shows the estimates of the treatment effect interacted with the dummy for higher than the country average rental price. Results indicate that living in a high rental price region significantly decreases the probability of being emancipated in the D-i-D specifications, with the effect being less precisely estimated in the RDD ones. The interaction between the treatment dummy and the higher rental price area is positive and statistically significant in most specifications. The estimated

\footnotetext{
${ }^{9}$ Note that, to facilitate interpretation, these regressions do not include a constant.
} 
effects indicate that eligibles experience increases in emancipation rates 1.4-2.6 percentage points higher in high-rental price regions compared to low rental price ones. This result is consistent with the theoretical predictions described in Section 2.2.

If high rental price regions feature different employment dynamics than low rental price regions, the coefficient would capture different business cycles aside from differences in the impact of the policy. We test the hypothesis of differential trends in regional employment by estimating the same equation but substituting the dependent variable with a dummy equal to one if the individual is employed and equal to zero otherwise. The interaction of interest is not significantly different from zero in all the specifications.

Emancipation across countries features a common pattern that consists in young women leaving the parental home earlier than men. Policies that alleviate financial constraints may imply further bifurcation in the transition to adulthood if they affect women's leaving decisions more than men's (Chiuri and Del Boca, 2010). We investigate whether this is the case in the policy under analysis by splitting the sample by gender. Women are 1.1-2.4 percentage points more likely than men to emancipate as a consequence of the subsidy, therefore confirming the intuition from Chiuri and Del Boca, 2010.

\subsection{Cohabitation and fertility}

After testing that the policy does not have any effect on marriage rates, we focus on couple cohabitation, and on fertility, conditioned on being emancipated. Cohabitation is defined with a dummy equal to one if the individual is part of a household with her partner, and zero otherwise. Fertility is a dummy equal to one if the emancipated individual has one or more children, and zero otherwise.

Table 6 shows the estimates of the treatment effect on couple cohabitation. Results, significant across all specifications, indicate that the probability of cohabiting increases by 1.2-2.4 percentage points. Relative to the 9.3 percent sample mean these coefficients correspond to an increase of 11-22 percent points. We replicate the same exercise we did for emancipation, and estimate the effect of the policy for different income levels and rental prices. Estimates in Table 7 show that cohabitation is positively correlated with income; however, the policy significantly increases couple cohabitation by 14-29 percentage points for those with lower income. The policy negatively affects couple cohabitation for those with income higher than $€ 500$ and lower than $€ 1,000$. Estimates in Table 8 show that the effect of the policy was stronger in high rental price areas, where couple cohabitation increased by 1.2-3.1 percentage points with respect to low rental price areas, consistently with the evidence presented in the previous Section.

As the theoretical analysis in Section 2.2 highlights, the policy is expected to have an income effect and hence, emancipated eligible youngsters are expected to consume more of other goods on average. Given that children are complementary to emancipation, we test the hypothesis that the policy has a positive impact on fertility. As the income effect is only present for emancipated eligible 
individuals, we restrict the analysis only to emancipated individuals. Table 9 shows the effect of the policy on the probability of having at least one child conditional on being emancipated. Given the natural delay between the decision to become parents and the child's birth, the chosen specifications are the Difference-in-Differences and the Regression Discontinuity at 12 months before and after the month individuals turns 22. Estimates indicate that the policy significantly increases fertility by 4.8-8.1 percentage points. Relative to the 27.1 percent sample mean this implies an increase of 13-22 percent. The effect of the policy does not vary with individual's income and rental prices.

\section{Robustness checks}

The estimations obtained from D-i-D and RDD methods are valid under different sets of assumptions and still are consistent with each other. Yet, to increase the confidence in our results, we run a battery of robustness checks.

The D-i-D specification is reliable under the assumption of a common time trend between treatment and comparison groups in the absence of the reform. If this assumption fails, our positive estimates may reflect differential time trends in emancipation between treatment and comparison groups, rather than a true policy impact. When examining this graphically (Graph 2), we find that the pre-policy trends of emancipation are quite similar for the treatment and the comparison groups, but that there is a sudden change in their relative outcomes after the policy. To provide further evidence for the existence of parallel trend before the policy change, we perform a placebo test and pretend that the policy was implemented in 2007 rather than 2008, using the 2006 sample as pre-policy. Differential time trends in treatment and control groups should cause these effects to be significantly different from zero. The first two columns of Table 10 present Difference-in-Differences estimates of the probability of being emancipated, cohabiting with the partner, and having children in the period from 2006 to 2007. The chosen specification includes the whole set of individual controls. The results show that none of the coefficients is significantly affected by the placebo policy. The overall results provide evidence for the robustness of the Di-D identification strategy, ruling out the hypothesis that the estimated effects in the previous section capture differential time trends.

Although it is reassuring to find that the trends are not systematically deviating in the pre-policy period, we may worry about breaks in the underlying trends coinciding with the policy. This could be the case if there were other policies that simultaneously affected 22 year-olds but not 21 year-olds. If this were the case, estimates from the D-i-D strategy would not capture the true effect of the rental subsidy because they would reflect the benefits of both the rental subsidy and other policy effects. The reform of the higher educational system, with the aim of adapting Spanish universities to the European Higher Education Area, slightly affects the length of university studies. ${ }^{10}$ It was approved in 2007,

\footnotetext{
${ }^{10}$ The pre-reform model for university studies offered first cycle education (short cycle), first and second cycle (long cycle), second-cycle only, and third cycle. With the 2007 reform,
} 
and some universities enacted it in 2008 , but the whole system was required to conform to the law by 2010 . We believe this does not constitute a threat to our identification strategy: even if some universities began offering the new courses in the 2008/09 academic year, the first students affected by this will graduate in July 2012. To be more convincing on this, we perform another placebo test, replacing the emancipation outcome with educational level. A significant effect of the reform on individuals' educational level would raise concerns that effects on emancipation reflect underlying changes in educational levels. However, we find no differential effects of the policy on educational levels for treatment and control groups. Moreover, we estimate the equation of interest excluding students as they may be enrolled in some of the new graduates courses offered after the educational reform. This does not affect our estimates.

The main concern for the RDD specification arises from the assumption that our results may be driven by pre-existing differences between 21 and 22 year-olds in their propensity to emancipate. Columns 3-10 of Table 10 present the results of another placebo test, where the RDD strategy is applied to the pre-policy period including the years 2006 and 2007. All coefficients are insignificant, ruling out the hypothesis of differential age trends between treatment and control groups.

All results are also consistent to the estimate of the main specification with another control group: that of young adults aged 20 years. This rules out that our results are driven by 21 years-old postponing emancipation until they become eligible for the subsidy.

We test the robustness of our results to an alternative functional form, a Probit model. Results are consistent to this alternative specification.

Finally, we analyze the extent to which the policy has general equilibrium effects on rental prices. If the policy also affects rental prices, regions with a higher fraction of eligibles should have experienced a sharper increase in rental prices after 2008. We tested this hypothesis using Fotocasa data and assuming each region is a separate market. Panel estimates of regional yearly variation in rental prices do not show any significant effect of the interaction between the fraction of eligibles (measured with the yearly proportion of 22-29 year-olds in each region) and the post-policy dummy.

\section{Conclusion}

Our paper estimates the effects of a cash transfer contingent on young adults renting accommodation on emancipation, couple cohabitation and fertility. Our identification strategy exploits the subsidy eligibility age threshold to assess the causal impact of the cash transfer.

Difference-in-Differences and Regression Discontinuity estimates show that the probability of being emancipated increases by $14-18$ percent and that the probability of cohabiting with the partner increased by $11-22$ percent for an eligible 22 year-old compared to a non-eligible 21 year-old. The increase is

education provision was structured into three cycles: bachelor, master and doctorate. 
sharper for youngsters at the lower tail of the income distribution and those living in high rental price areas, consistent with the hypothesis that young adults in Southern Europe delay emancipation and family formation because they are budget constrained. Additional evidence indicates that the policy also affects fertility decisions, as among emancipated youngsters eligibles increased the probability of having a child by $13-22$ percent.

The stronger effect of the policy for individuals earning low incomes suggests that the program should be targeted to poorer individuals. Moreover, the higher impact of the policy for young adults living in high rental price regions indicates that the policy design should take into account not only individual's income but also housing prices. This would allow the policy to remove barriers to emancipation for young adults who are too poor to afford renting accommodation, while limiting the cost of the program and its negative impact through potential general equilibrium effects.

The policy may have consequences on labour supply and consumption as well. We consider those important directions for future research. 


\section{References}

[1] Becker, S. O., Bentolila, S., Fernandes, A., Ichino, A. (2010) "Youth Emancipation and Perceived Job Insecurity of Parents and Children", Journal of Population Economics, Vol 23(3), pp. 1047-1071.

[2] Card, D., Lee, D. (2008) "Regression Discontinuity Inference with Specification Error", Journal of Econometrics, Vol. 142(2), pp.655-674.

[3] Chiuri, M.C., Del Boca, D. (2010) "Home-Leaving Decisions of Daughters and Sons", Review of Economics of the Household, Vol 8(3), pp. 393-408.

[4] Ermish, J. (1999) "Prices, Parents, and Young People's Household Formation", Journal of Urban Economics 45, 47-71

[5] Garcia-Ferreira, M., Villanueva, E. (2007). "Employment Risk and Household Formation: Evidence from Differences in Firing Costs." Banco de España Working Paper No. 737

[6] Giannelli, G. C., Monfardini, C. (2003) "Joint Decisions on Household Membership and Human Capital Accumulation of Youths. The Role of Expected Earnings and Local Markets", Journal of Population Economics, Vol 16(2), pp. 265-285.

[7] Giuliano, P. (2007) "Living Arrangements in Western Europe: Does Cultural Origin Matter?", Journal of the European Economic Association, Vol 5(5), pp. 927-952.

[8] Hahn, J., Todd P., and van der Klaauw W. (2001) "Identification and Estimation of Treatment Effects with a Regression-Discontinuity Design." Econometrica, Vol 69(1), pp. 201-09.

[9] Lee, D. (2008) "Randomized Experiments from Non-random Selection in U.S. House Elections" Journal of Econometrics, Vol. 142(2), pp. 675-697.

[10] Lee, D., Lemieux, T. (2010) "Regressions Discontinuity Designs in Economics", Journal of Economic Literature. Vol. 48, pp. 281-355.

[11] Imbens, G., Lemieux, T. (2008) "Regression Discontinuity Design: a Guide to Practice", Journal of Econometrics, Vol. 142(2), pp. 615-635

[12] Manacorda, M., Moretti, E. "Why do Most Italian Youths Live with their Parents? Intergenerational Transfers and Household Structure", Journal of the European Economic Association, Vol 4(4), pp. 800-829.

[13] Martínez-Granado, M., Ruiz-Castillo, J. (2002). "The Decisions of Spanish Youth: a Cross-Section Study." Journal of Population Economics, 15, 305330. 
[14] Martins, N., Villanueva, E. (2009) "Does High Cost of Mortgage Debt Explain Why Young Adults Live with Their Parents?", Journal of the European Economic Association, Vol 7(5), pp. 974-1010.

[15] Susin, S. (2002) "Rent Vouchers and the Price of Low-Income Housing", Journal of Public Economics, Vol. 83, pp. 109-152.

[16] Van Der Klaauw, W. (2008) "Regression Discontinuity Analysis: a Survey of Recent Developments in Economics", Labour, Vol. 22(2), pp. 219-245. 


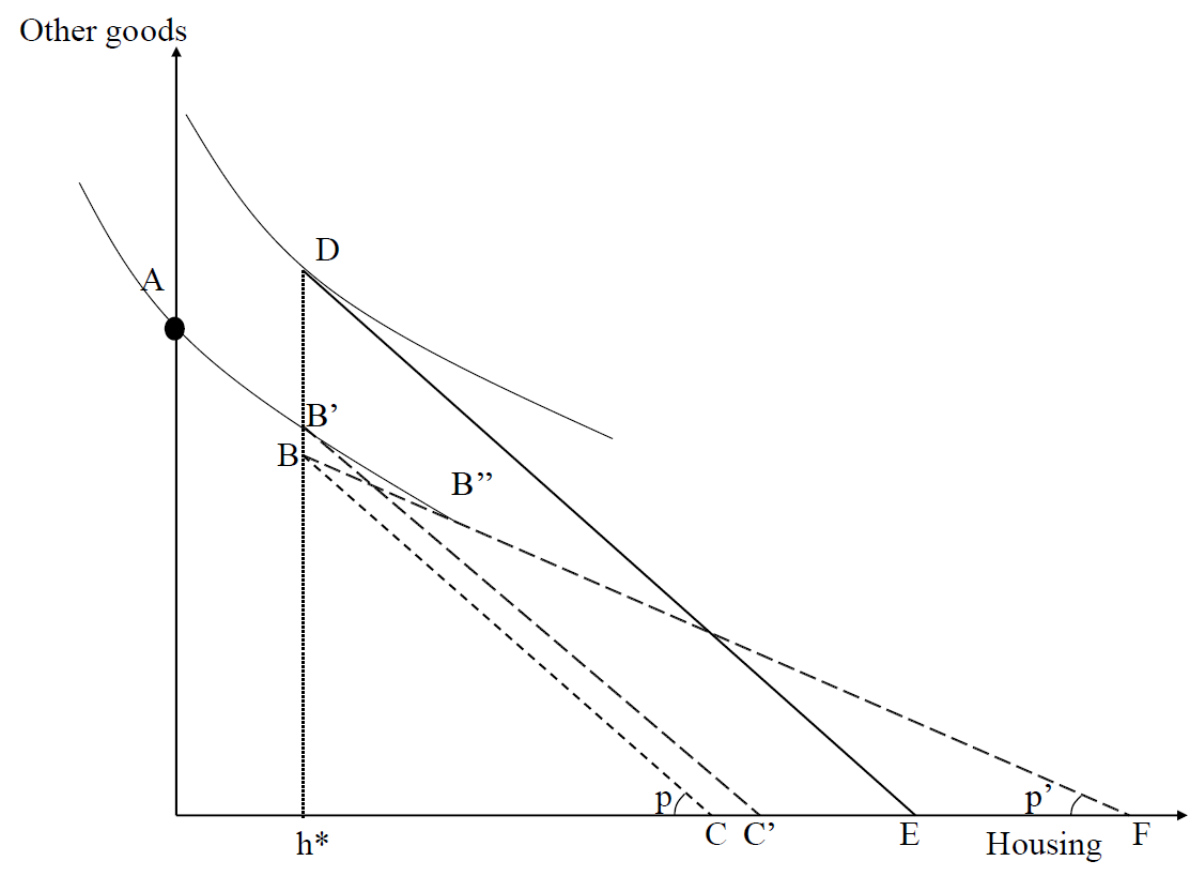

Figure 1: The effect of conditional cash transfer on emancipation 


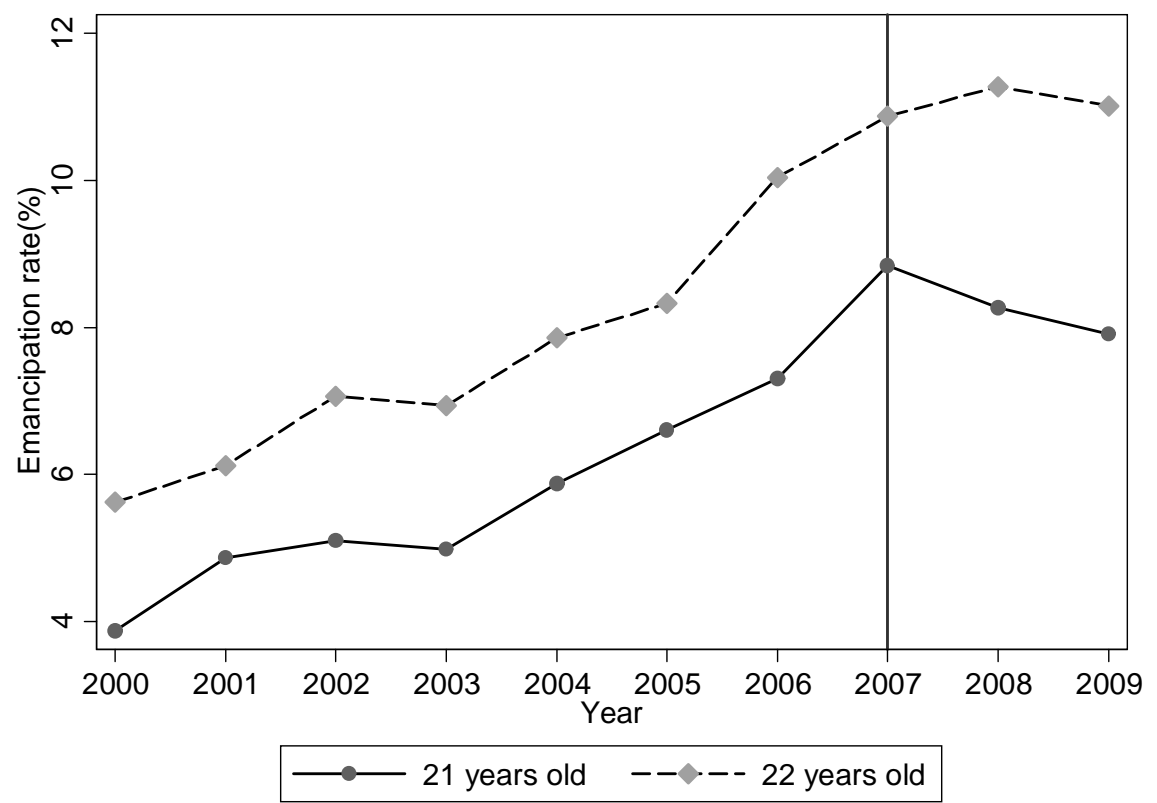

Figure 2: Trends of average rate of emancipation for treatment and control group using LFS data. 


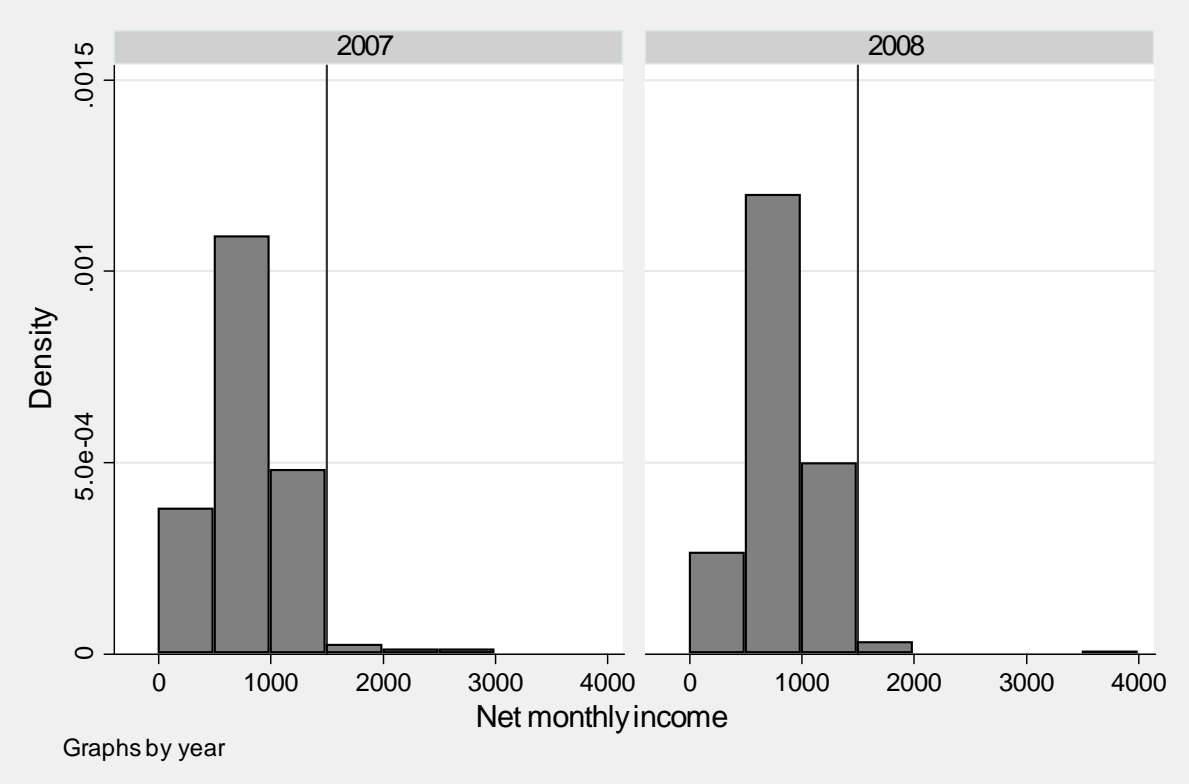

Figure 3: Histogram of net monthly income intervals of 22 year-olds, HBS 2007 and 2008 


\begin{tabular}{|c|c|c|c|c|}
\hline & Mean & St. dev. & Min & $\operatorname{Max}$ \\
\hline \multicolumn{5}{|l|}{ Panel A - LFS: 28,185 obs } \\
\hline Emancipated & 0.156 & 0.363 & 0 & 1 \\
\hline Cohabiting with partner & 0.093 & 0.290 & 0 & 1 \\
\hline Having kids, conditional on emancipation & 0.271 & 0.445 & 0 & 1 \\
\hline 2008 sample & 0.497 & 0.5 & 0 & 1 \\
\hline Age 22 or more & 0.510 & 0.5 & 0 & 1 \\
\hline Age & 21.510 & 0.500 & 21 & 22 \\
\hline Male & 0.506 & 0.5 & 0 & 1 \\
\hline Immigrant & 0.135 & 0.342 & 0 & 1 \\
\hline Secondary education & 0.801 & 0.399 & 0 & 1 \\
\hline Tertiary education & 0.108 & 0.301 & 0 & 1 \\
\hline \multicolumn{5}{|l|}{ Panel B - HBS: 2,768 obs } \\
\hline Emancipated & 0.188 & 0.391 & 0 & 1 \\
\hline Cohabiting with partner & 0.059 & 0.236 & 0 & 1 \\
\hline Having kids, conditional on emancipation & 0.236 & 0.425 & 0 & 1 \\
\hline 2008 sample & 0.494 & 0.500 & 0 & 1 \\
\hline Age 22 or more & 0.534 & 0.499 & 0 & 1 \\
\hline Age & 21.534 & 0.499 & 21 & 22 \\
\hline Male & 0.520 & 0.500 & 0 & 1 \\
\hline Immigrant & 0.170 & 0.375 & 0 & 1 \\
\hline Secondary education & 0.424 & 0.494 & 0 & 1 \\
\hline Tertiary education & 0.222 & 0.415 & 0 & 1 \\
\hline Monthly net income & 875.2 & 347.7 & 90.0 & 3831.3 \\
\hline Income less than Euro 500 & 0.129 & 0.336 & 0 & 1 \\
\hline Income bw Euro 500-1000 & 0.644 & 0.479 & 0 & 1 \\
\hline Income bw Euro 1000-1500 & 0.200 & 0.401 & 0 & 1 \\
\hline \multicolumn{5}{|l|}{ Panel C - Fotocasa: 17 obs } \\
\hline Average rental price, Euro/m2 & 8.372 & 2.107 & 5 & 12.2 \\
\hline Regions above average price & 0.353 & 0.493 & 0 & 1 \\
\hline
\end{tabular}

Means weighted by sample weights.

Table 1: Descriptive Statistics 


\begin{tabular}{|c|c|c|c|}
\hline & \multicolumn{2}{|c|}{ Program eligibility } & \multirow[b]{2}{*}{ Difference } \\
\hline & 22 years old & 21 years old & \\
\hline \multicolumn{4}{|l|}{ Emancipation } \\
\hline 2008 sample & $\begin{array}{c}0.176 \\
(0.018)\end{array}$ & $\begin{array}{c}0.129 \\
(0.017)\end{array}$ & $\begin{array}{c}0.047 \\
(0.007)\end{array}$ \\
\hline 2007 sample & $\begin{array}{c}0.164 \\
(0.015)\end{array}$ & $\begin{array}{c}0.144 \\
(0.016)\end{array}$ & $\begin{array}{c}0.020 \\
(0.006)\end{array}$ \\
\hline Difference & $\begin{array}{c}0.012 \\
(0.017) \\
\end{array}$ & $\begin{array}{l}-0.015 \\
(0.017)\end{array}$ & $\begin{array}{c}\mathbf{0 . 0 2 7} \\
(0.007)^{* * *}\end{array}$ \\
\hline \multicolumn{4}{|l|}{ Cohabitation } \\
\hline 2008 sample & $\begin{array}{c}0.111 \\
(0.017)\end{array}$ & $\begin{array}{c}0.070 \\
(0.016)\end{array}$ & $\begin{array}{c}0.041 \\
(0.007)\end{array}$ \\
\hline 2007 sample & $\begin{array}{c}0.095 \\
(0.018)\end{array}$ & $\begin{array}{c}0.086 \\
(0.018)\end{array}$ & $\begin{array}{c}0.009 \\
(0.007)\end{array}$ \\
\hline Difference & $\begin{array}{c}0.016 \\
(0.015) \\
\end{array}$ & $\begin{array}{l}-0.016 \\
(0.017) \\
\end{array}$ & $\begin{array}{c}\mathbf{0 . 0 3 2} \\
(0.007)^{* * *}\end{array}$ \\
\hline \multicolumn{4}{|c|}{$\begin{array}{l}\text { Fertility - conditional on eman- } \\
\text { cipation }\end{array}$} \\
\hline 2008 sample & $\begin{array}{c}0.309 \\
(0.048)\end{array}$ & $\begin{array}{c}0.208 \\
(0.066)\end{array}$ & $\begin{array}{c}0.101 \\
(0.023)\end{array}$ \\
\hline 2007 sample & $\begin{array}{c}0.275 \\
(0.088)\end{array}$ & $\begin{array}{c}0.256 \\
(0.110)\end{array}$ & $\begin{array}{c}0.019 \\
(0.042)\end{array}$ \\
\hline Difference & $\begin{array}{c}0.034 \\
(0.106)\end{array}$ & $\begin{array}{l}-0.048 \\
(0.128)\end{array}$ & $\begin{array}{c}\mathbf{0 . 0 8 2} \\
(0.049)^{*}\end{array}$ \\
\hline
\end{tabular}

Note: LFS data. Means and standard errors in brackets; ${ }^{* * *}$ significant at 1 percent; * significant at 10 percent.

Table 2: Means of emancipation by year of interview and eligibility status 


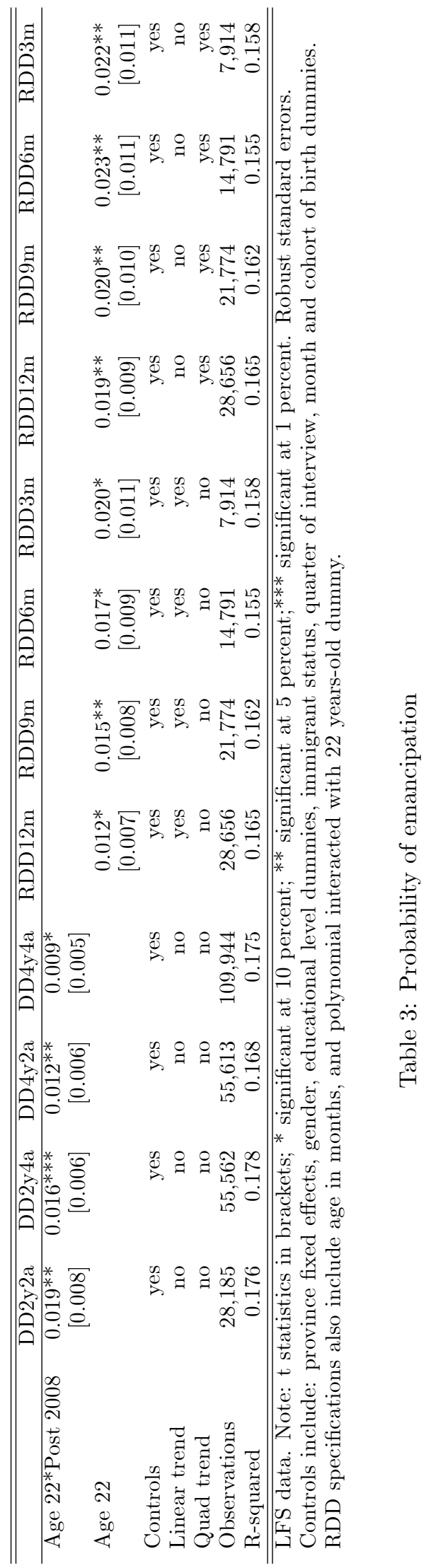




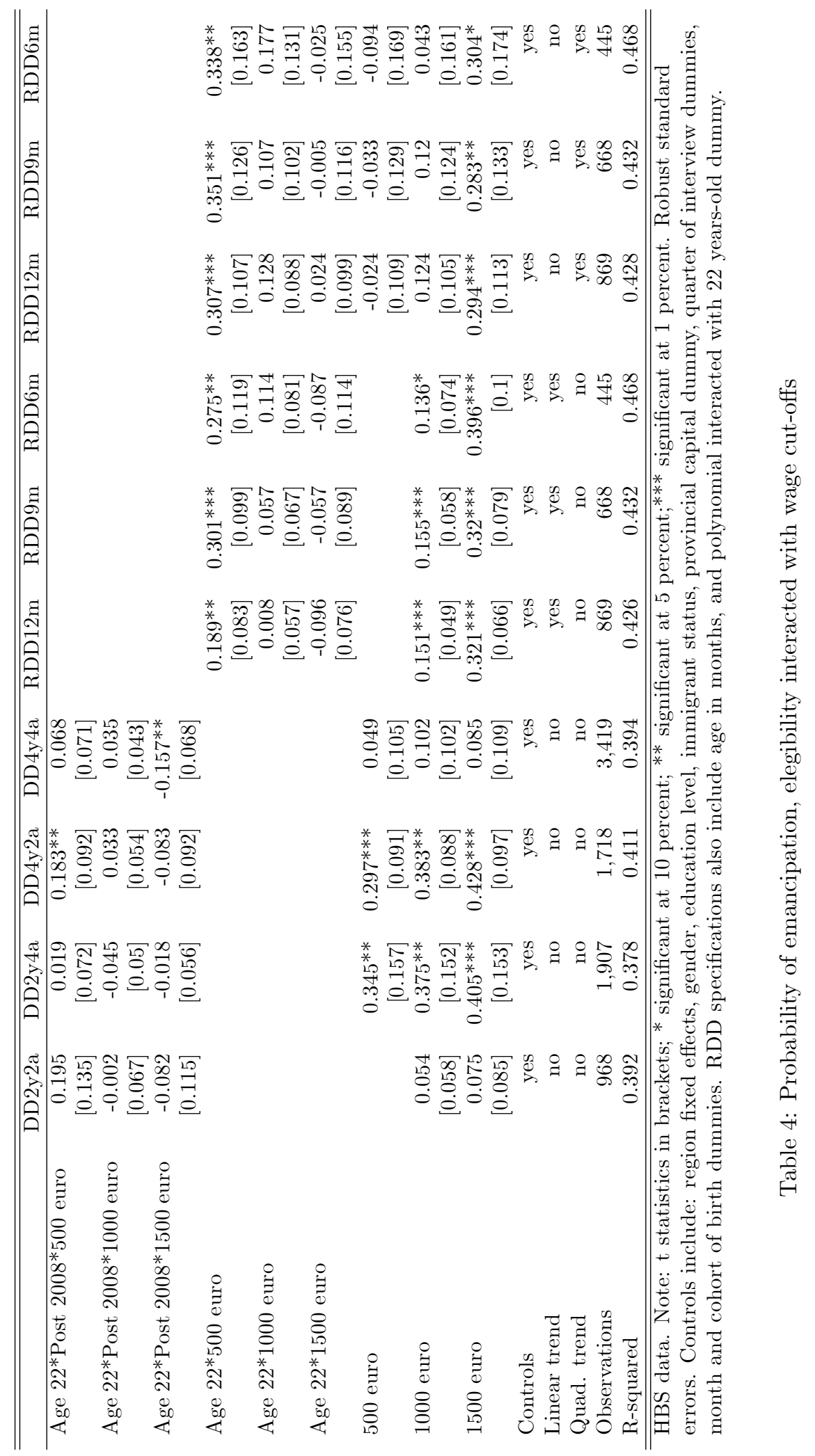




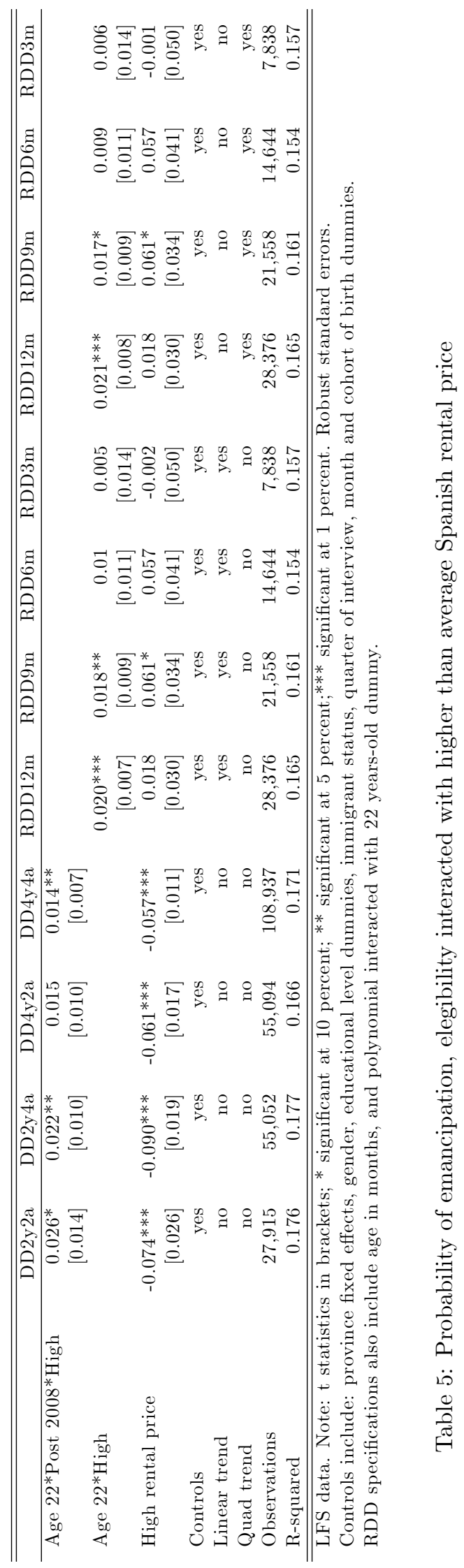




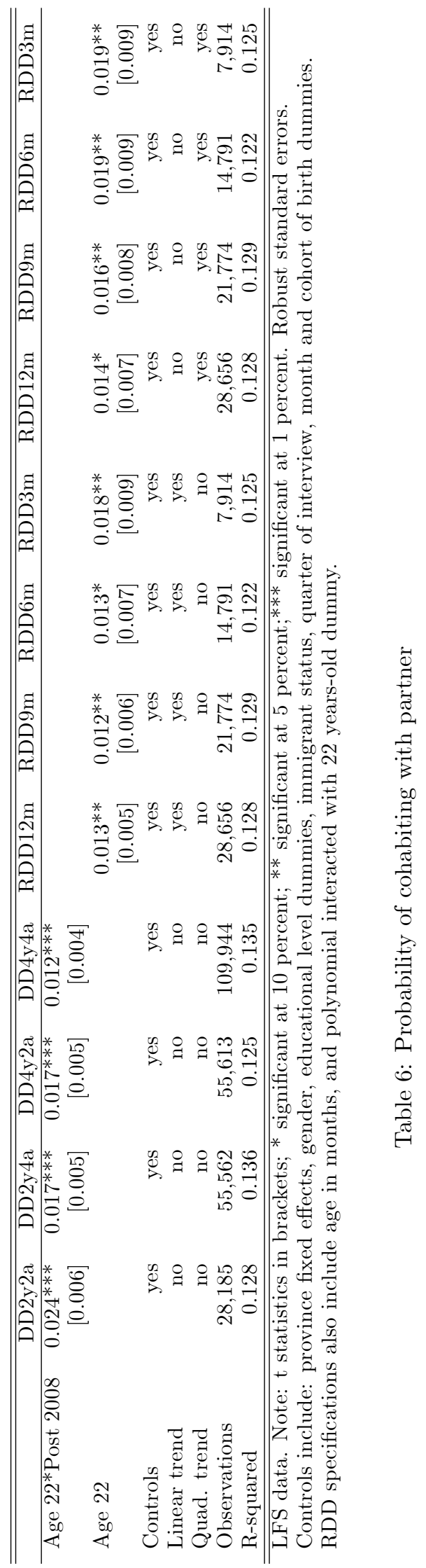




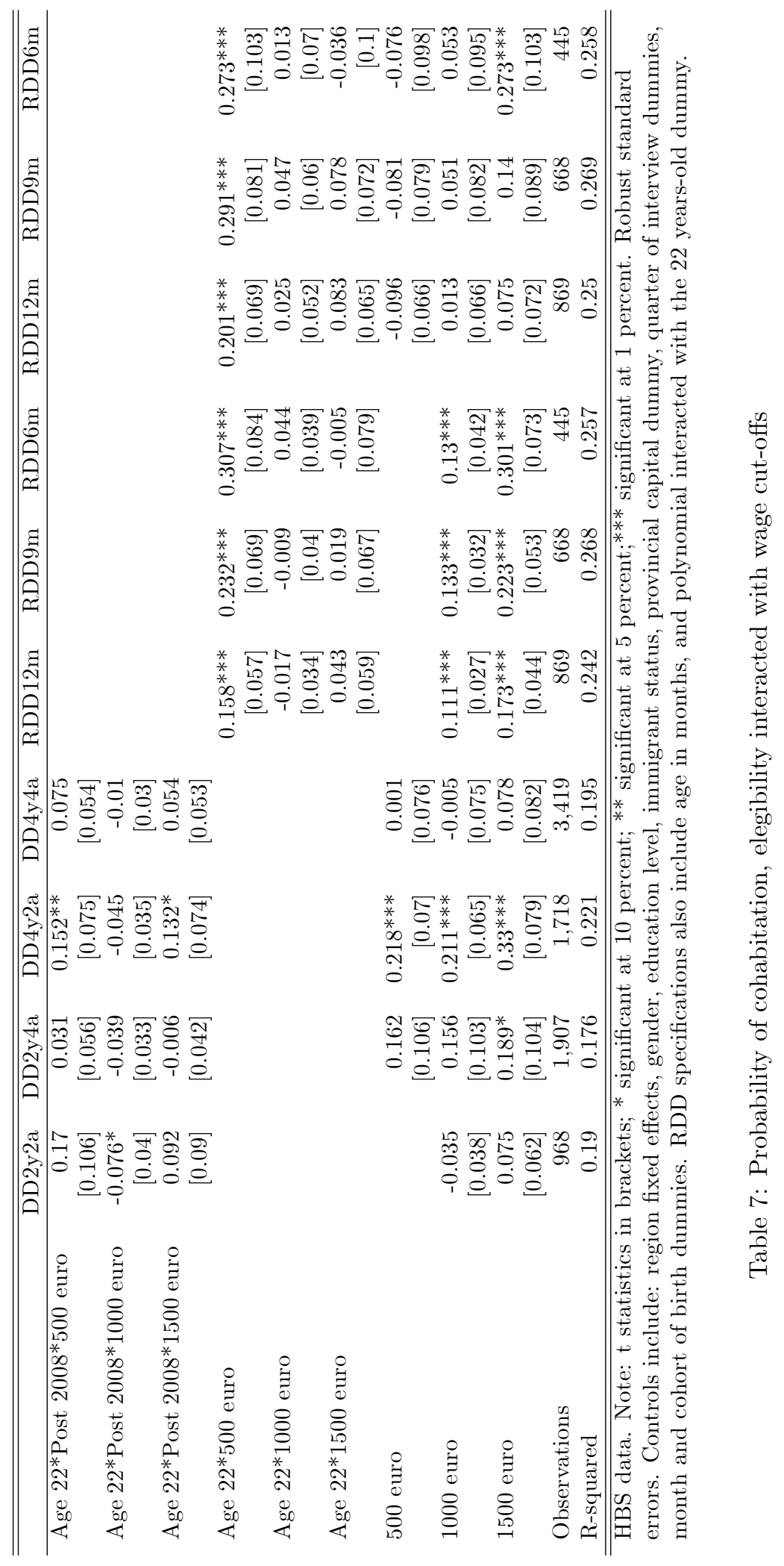




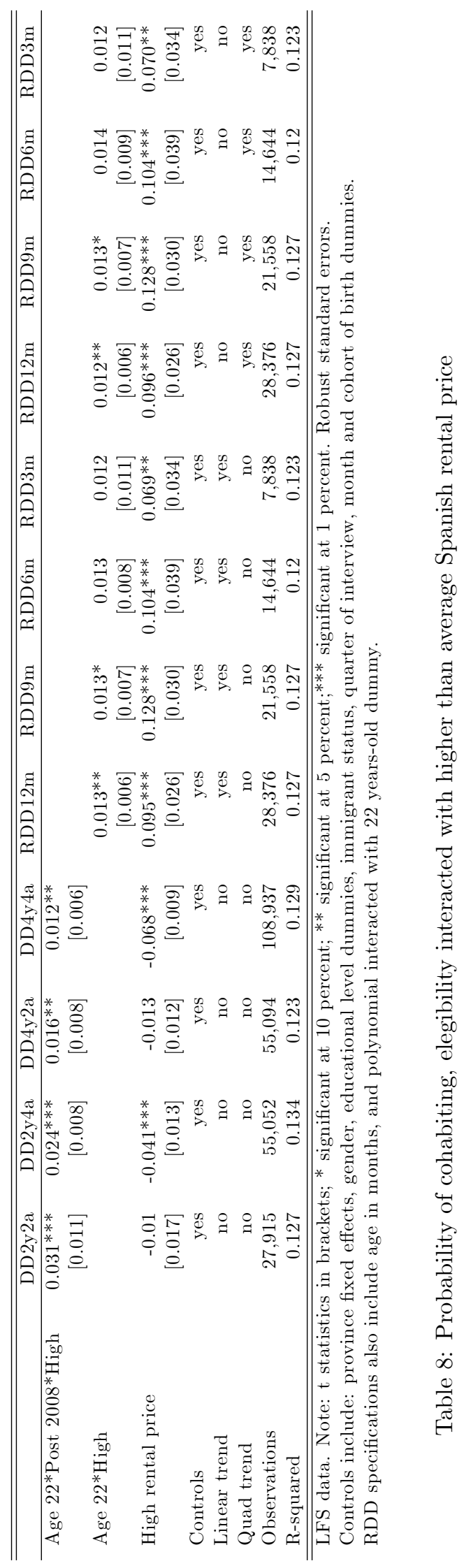




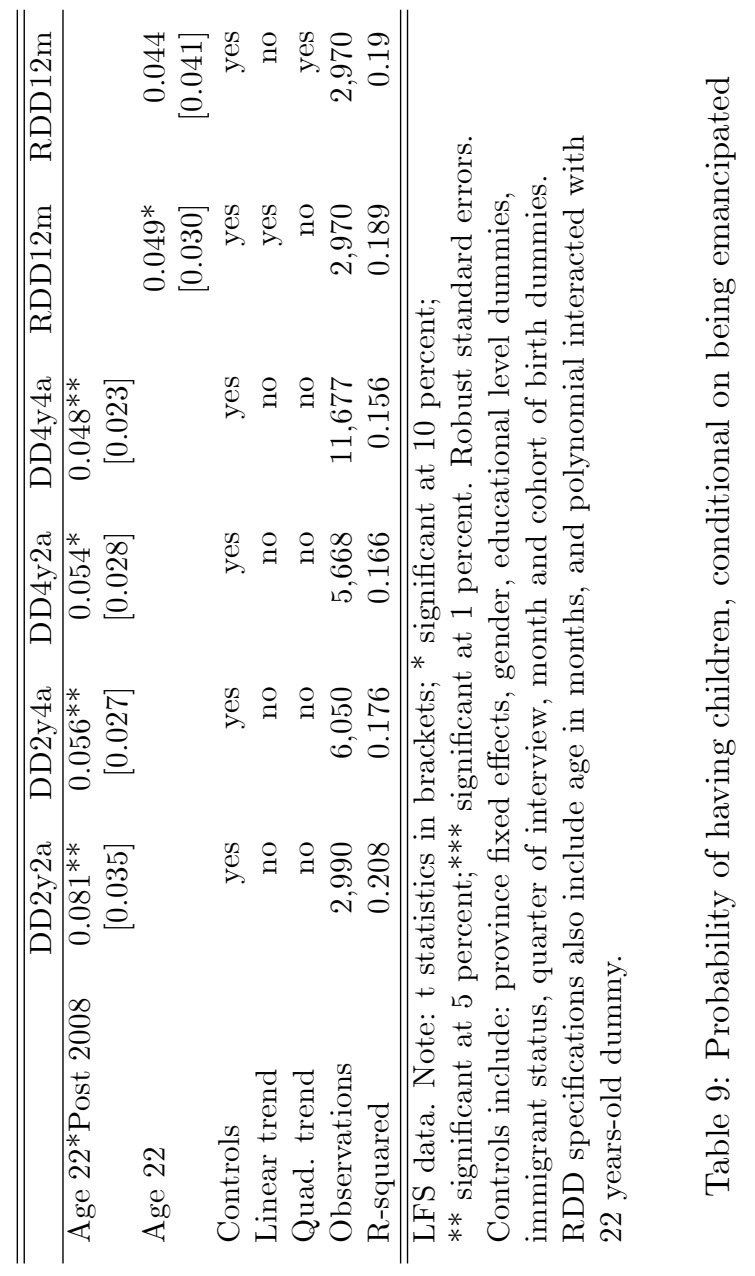




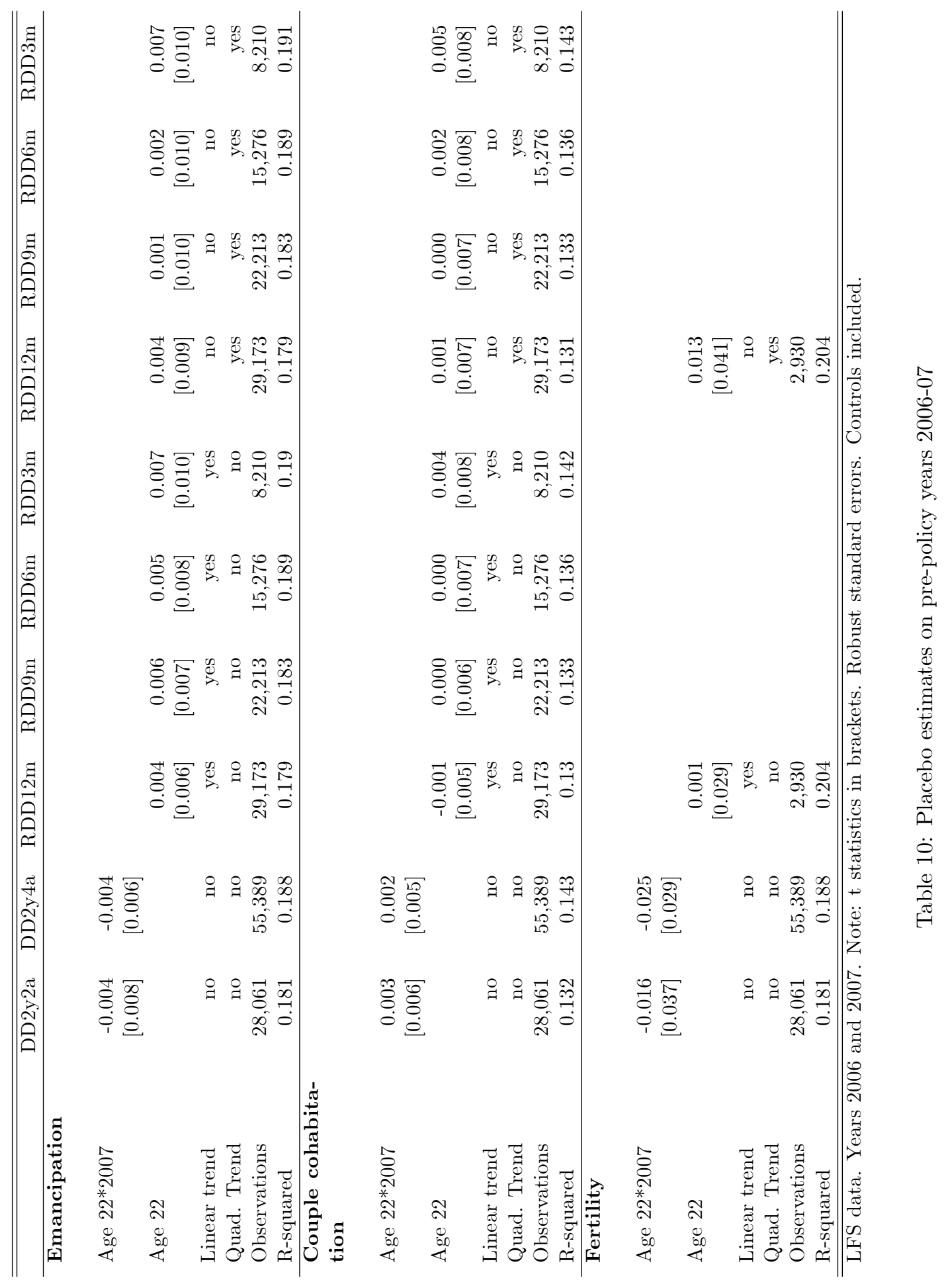

